Man setzt den feingestossenen Graphit, je nach seiner Unreinheit mit 100 bis 200 p.C. eines Gemenges von gleichen Theilen Soda und Schwefel gemischt, einer mässigen Rothgluhbitze aus, bis die blaue Schwefelflamme, welche anfangs unter dem Tiegeldeckel herausbrennt, verschwunden ist und einer kleinen von gelber Farbe Platz gemacht hat. Die schwach gesinterte Masse wird nach dem Erkalten mit Wasser aufgekocht und durch Decantiren ausgewaschen; den Ruckstand behandelt man mit verdunnter Salzsäure, welche unter Schwefelwasserstoffentwickelung alles vorhandene Eisen auflöst. Hierbei geräth der Graphit in den Zustand sehr feiner Vertheilung und braucht lange Zeit zum Absitzen, indess kann man diesem Uebelstande durch Auswaschen mit Salmiaklösung völlig begegnen.

Der auf solche Weise erhaltene Graphit lässt beim Verbrennen nur noch einen geringen Ruckstand von schneeweisser Kieselsäure; um auch diese zu entfernen, kocht man ihn mit wenig Natronlauge, wäscht abermals aus, trocknet und erhitzt das nun fertige Präparat im bedeckten Tiegel zum gelinden Gluhen, wobei es dichteren Zustand annimmt.

Nach diesem Verfahren wurde aus dem ordinärsten Graphit ein Product erhalten, welches beim Verbrennen keine Spur von Asche hinterliess.

\title{
LXXVIII.
}

\section{Ueber Indiumgewinnung.}

\section{Von}

Dr. Cl. Winkler.

Die Methode, welche Böttger zur Gewinnung von Indium aus Flugstanb anwendete und in diesem Journal 98, 26 mitgetheilt hat, empfieblt sich durch grosse Einfachbeit und Bequemlichkeit in der Ausfuhrung. Indessen scheint sie nicht auf alle indiumbaltigen Materialien mit demselben Erfolge anwendbar zu sein, wie ibn Bottger bei Verarbeitung des zinkischen Ofenrauchs von der Juliushtitte bei Goslar erreichte. 
Ich versuchte das in Rede stehende Verfahren zur Darstellung von Indium aus Zink anzuwenden:

$20 \mathrm{Pfd}$. Freiberger Zink wurden in verdinnter Schwefelsäure gelöst und in die erhaltene Zinkvitriollauge Zinkplatten gestellt. Nach Verlauf von 24 Stunden, während welcher Zeit häufig umgerthrt wurde, fand sich in der filtrirten Losung noch viel Indium; dasselbe war auch nach drei Tagen noch der Fall und selbst nach zweiwöchentlichem Stehen war die Ausfällung des Indiums nicht rollständig, wenn auch zum grôssten Theile erfolgt. Erhitzte man dagegen das Ganze zum Sieden, so fand sich nach Verlauf einer Stunde keine Spur von Indium mehr im Filtrat, wenn man eine Probe desselben mit Ammoniak bis zur Wiederauflösung des ausgeschiedenen Zinkoxyds versetzte und den verbliebenen geringen Niedersehlag spectralanalytisch prufte.

Das in der Flussigkeit suspendirte schwarze Metallpulver, aus Indium, Cadmium, Blei, Kupfer, Arsen etc. bestehend, wurde, nach Böttger's Vorschrift, abfiltrirt und mit siedendem Wasser so lange ausgewaschen, bis Schtwefelammonium keine Reaction mehr gab. Hierauf wurde es in eine Schale gespult und mit einer concentrirten Auflosung von Oxalsäure eine halbe Stunde lang gekocht. Nach dem Verdunnen wurde der Ruckstand durch Filtration von der Flussigkeit getrennt; das Filtrat zeigte tiefgelbe Farbe und enthielt neben Indium auch fast alles vorhanden gewesene Eisen, sowie etwas Cadmium, Zink und Blei. Thallium war nicht nachzuweisen. Beim Erkalten begann die Lösung sich zu truben und einen weissen, schleimigen Niederschlag abzusetzen, der das meiste Indium, jedoch ebenfalls durch genannte Metalle verunreinigt, enthielt; die daruber stehende Lösung gab mit Ammoniak einen gelben Niederschlag, der sich allmählich dicht und körnig zusammensetzte und sich fest an die Gefässwände anlegte. In ihm fand sich hauptsächlich Eisen, sowie ein weiterer Theil Indium vor.

Der nach der ersten Auskochung verbliebene Ruckstand wurde nochmals mit heisser Oxalsäure behandelt, wobei nur noch sehr wenig Indium in Lösung ging. Hierauf wurde er, um ihn auf einem etwa noch immer darin rerbliebenen In- 
diumgehalt zu prtfen, mit Salpetersaure oxydirt, das Blei durch Verdampfen mit Schwefelsäure abgeschieden, der Rtickstand in Wasser aufyenommen und die erhaltene Flussigkeit mit Ammoniak ubersattigt; es ergab sich dabei, dags ein Viertel bis ein Drittel des tberbaupt vorhanden gewesenen Indiums dem lösendén Angriffe der Oxalsäure entgangen war.

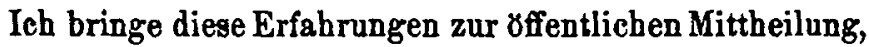
obne die Genauigkeit der Bottger'schen Angaben irgendwie anzweifeln zu wollen, zumal es allgemein bekannt ist, dass ein und derselbo Verarbeitungsweg auf Rohmaterialien von verschiedener Natur angewendet, auch zu ganz abweichenden Ergebnissen fubren kann.

\section{LXXIX.}

\section{Ueber Chromeyanverbindungen.}

Durch Wechselzersetzung von reinem Cyankalium mit Chromalaun kann man nach A. Kaiser (Ann. d. Chem. u. Pharn. 3. Supplem. p. 163) je nach der Menge der beiden in Wechselwirkung tretenden Salze dreierlei Verbindungen darstellen, welche Chrom, Cyan und Kalium enthalten. Von diesen ist jedoch nur eine krystallisirbar und mit gut charakterisirten Eigenschaften versehen, während die beiden anderen gummiartige mit mannigfachen Zersetzungsproducten untermischte Substanzen sind.

Die krystallisirbare Verbindung, Kaliumchromcyanid, $3 \mathrm{KCy}, \mathrm{CrCy}_{3}$, bildet sich beim Vermischen einer heissen Losung von $6 \mathrm{Th}$. KCy mit $5 \mathrm{Th}$. Chromalaun; nach längerem Erhitzen unter Ersatz des verdampiten Wassers wird zu der erkalteten Flussigkeit Alkohol hinzugefugt und das Filtrat von dem dabei entstehenden Niederschlag eingedamptt. Die resultirende Salzmasse reinigt man durch Umkrystallisiren bis reine hellgelbe Krystalle von der Form des rothen Blutlaugensalzes anschiessen. Diese haben die oben angegebene Zusammensetzung, lösen sich in $3,24 \mathrm{Th}$. Wasser von $+15^{\circ} \mathrm{C}$, gar nicht in absolutem, aber beträchtlich in verdtuntem Alkohol. Ihre wässerige Lösung zersetzt sich nicht, wird durch 